\title{
La infancia y sus derechos en los desahucios de Gipuzkoa ${ }^{1}$
}

\author{
Joana Miguelena Torrado \\ Grupo de Estudios Históricos y Comparados en Educación-Garaian \\ Universidad del País Vasco/Euskal Herriko Unibertsitatea (UPV/EHU) \\ <joana.miguelena@ehu.eus>
}

Krisi ekonomikoak Euskadiko eta Espainiako haurren pobrezia-egoera larritu eta gizarte-bazterkerian erortzearen arriskua areagotu du. Krisiaren adibideetako bat izan daiteke etxe kaleratze batengatik etxea galdu duten haurren kopurua. Hori dela-eta, artikulu honekin, etxe kaleratzeen fenomenoa testuinguruan jartzeaz gain, etxea galtzear dauden haur horien errealitatera gerturatzea dugu helburu. Gerturatze hori, 1989ko Nazio Batuen Haurren Eskubideei buruzko Hitzarmenean jasotzen diren Oinarrizko Eskubideen irakurketaren bidez egin dugu. Horretarako, haurren eskubideen babesean ardura duten eta horretan diharduten pertsona desberdinen testigantzak aztertu ditugu kualitatiboki. Emaitzek, etxe kaleratze prozesuak haurren eskubideetan eragina izateaz aparte, beraien bizitzako beste hainbat eremuetan eragina dutela erakusten dute.

\section{GAKO-HITZAK:}

Etxegabetzeak, haurtzaroaren eskubideak, Haurren Eskubideei buruzko Hitzarmena, gizarte-bazterketa.
La crisis económica ha agravado la situación de pobreza y ha incrementado el riesgo de exclusión social de la infancia vasca y española. Ejemplo de ello es el número de niñas y niños que han perdido su casa a causa de un desahucio. En este artículo, aparte de contextualizar este fenómeno de la pérdida de vivienda, nos acercaremos a la realidad de la infancia inmersa en un proceso de desahucio, a través de una lectura de los derechos transversales recogidos en la Convención sobre los Derechos del Niño de Naciones Unidas de 1989. Para ello, se han recogido y analizado cualitativamente las voces de distintos agentes encargados de proteger y salvaguardar los derechos de las niñas y niños. Los resultados muestran cómo el proceso de desahucio no solamente afecta a sus derechos y su protección, sino también a otros ámbitos de su vida.

\section{Palabras Clave:}

Desahucios, derechos de la infancia, Convención sobre los Derechos del Niño, exclusión social. 


\section{La crisis económica en las familias}

La crisis financiera, iniciada a finales de 2007 , ha ocasionado que la calidad de vida de muchas de las familias vascas y españolas haya empeorado de una manera significativa. La pérdida de empleo, los altos índices de paro, los recortes económicos, el aumento del índice de pobreza y el incremento de los desahucios son ejemplo de ello. La falta o disminución de ingresos en los hogares está deteriorando la calidad de la alimentación, las condiciones en el hogar y la convivencia en las relaciones intrafamiliares (Unicef, 2012; Cáritas, 2013), lo cual está afectando, a su vez, a la educación y al ocio de las niñas y niños (Unicef, 2012; Comisario de los Derechos Humanos del Consejo de Europa, 2013).

La crisis económica y, con ella, el aumento del paro en Euskadi, ha llevado a que cada vez un mayor número de hogares tengan dificultades para hacer frente a sus obligaciones económicas y gastos habituales. La tendencia general es recortar primero los gastos más superfluos y esperar a reducir después los de primera necesidad. Según datos del Ararteko (2013a), un $16,7 \%$ de las familias ya habían tenido que recortar gastos de primera necesidad en sus hogares, un porcentaje que duplicaba el registrado cuatro años atrás. Los cortes de suministros (luz, agua, teléfono), los problemas graves de alimentación, los embargos, los cambios de vivienda o de colegio, o la demanda de ayudas sociales son expresiones de la precariedad y la pobreza que están afectando a un sector cada vez mayor de la población vasca (Gobierno Vasco, 2012). El Ararteko (2013a) señalaba que 66.458 niños y niñas menores de 15 años en Euskadi, un 22,2\% de esa población, estaban en riesgo de no poder mantener unos niveles mínimos de bienestar.

\section{Los desahucios y su influencia en la infancia}

Las ejecuciones de hipotecas son los procedimientos judiciales que dan pie al embargo de una vivienda y permiten exigir el pago de las deudas hipotecarias. Si el deudor o deudora no satisface las cuentas pendientes, la vivienda se subasta y el proceso suele concluir con el desalojo o desahucio (Ararteko, 2013a). Este contexto de crisis ha provocado que muchas de las personas que suscribieron una hipoteca se vean obligadas a dejar de pagar las cuotas mensuales a la entidad financiera, lo que conlleva penalizaciones que incrementan sus deudas, en un momento en el que el precio de la vivienda ha sufrido una gran caída. A menudo, esta dinámica de impago culmina, especialmente en los hogares más vulnerables, en embargos y desahucios.

El Consejo General del Poder Judicial contabiliza 216.418 desahucios en España desde 2008 (Consejo General del Poder Judicial, 2013). El informe realizado por Ada Colau y Adriá Alemany (2013), en cambio, los cifra en 362.776 entre 2008 y 2012. Una nota de prensa emitida por el Banco de España el 18 mayo de
2014, constata que a lo largo de 2013 había habido 49.694 desahucios, lo que supondría una media de 136 al día (Banco de España, 2014).

En Euskadi, de acuerdo con los datos ofrecidos por el Ararteko (2013b), entre 2007 hasta 2011 se habrían ejecutado 5.173 desahucios. En cambio, Colau y Alemany (2013), hasta el segundo trimestre de 2012, cifran en 6.337 los llevados a cabo en Euskadi, de los cuales, 1.572 tuvieron lugar en Gipuzkoa. Hay que mencionar que no encontramos datos del Consejo General del Poder Judicial sobre las ejecuciones hipotecarias llevadas a cabo ni en Euskadi ni en Gipuzkoa.

En 2013, la Plataforma de Afectados por la Hipoteca (PAH), junto con el Observatori DESC, realizaron una investigación basada en 11.561 encuestas dirigidas a personas afectadas que habían contactado con la entidad en los últimos dos años. Los resultados mostraban que el paro era el motivo de impago en el $70 \%$ de los casos, que el $82 \%$ de las personas afectadas habían nacido en España, que el 59\% tenían estudios secundarios o universitarios, y que cerca de un $75 \%$ tenían al menos una hija o un hijo menor de 18 años (Valiño, 2013).

Aunque no es posible constatar de forma separada cuántas familias con hijas e hijos se han visto afectadas en procesos de ejecuciones hipotecarias o de un desahucio, el creciente número de éstos desde 2007 hace suponer que la influencia sobre las niñas y los niños de la pérdida del domicilio familiar ha sido importante, y ha afectado y condicionado su calidad de vida, oportunidades y derechos (Unicef, 2012; Comisario de los Derechos Humanos del Consejo de Europa, 2013).

Nils Muižnieks, el Comisario de los Derechos Humanos del Consejo de Europa, tras una estancia en España en 2013, elaboró un informe sobre la situación de pobreza en la que se encontraban los niños y las niñas tras los recortes sociales, sanitarios y educativos llevados a cabo por el Estado español. En él, hacía referencia a la considerable influencia de los desahucios en el disfrute de los derechos humanos de las niñas y los niños. Según el informe, los desahucios generaban altos niveles de estrés y grave perturbación en la vida de las niñas y los niños, especialmente en aspectos como la educación y la salud. Cuando estos desalojos se llevaban a cabo por agentes del orden, eran, a menudo, traumáticos para las niñas y los niños, ya que solían dar lugar a peores condiciones de vivienda $y$, en el peor de los casos, a la falta de vivienda, por la ausencia de previsión de un alojamiento alternativo adecuado y asequible. A su vez, indicaba que los desalojos habían llevado a menudo a la exclusión social de las personas desalojadas, incluidas las niñas y los niños, dado que las familias desalojadas a veces se abstenían de solicitar la asistencia de los servicios sociales, por temor a ser privadas de la custodia.

Al hilo de lo que denunciaba el comisario, a menudo, las familias que se han visto afectadas por un 
desahucio se han visto abocadas a la exclusión social. Por ello, creemos oportuno definir cuál es el concepto de exclusión social que nos permitirá, en apartados posteriores, correlacionar las realidades observadas con este término. Tradicionalmente, los conceptos de pobreza y exclusión social se han entendido y utilizado de manera indistinta, pero las diferencias son claras, ya que responden a causas distintas, se miden mediante indicadores diferentes y, sobre todo, se abordan mediante políticas y dispositivos distintos.

Las situaciones de pobreza se refieren básicamente a la carencia o falta de recursos materiales o económicos. Tienen una dimensión esencialmente monetaria, que se define fundamentalmente a partir de la renta de las familias, pero no presuponen, en sí mismas, situaciones de exclusión o marginación (SIIS Centro de Documentación y Estudios, 2013). La exclusión social, por su parte, es multidimensional, es una acumulación de dificultades en los ámbitos que normalmente determinan la inclusión de una persona en la sociedad: empleo, vivienda, salud, educación, relaciones personales, participación política y social, o recursos económicos, entre otras. La pobreza o insuficiencia de recursos materiales y económicos es uno de los elementos que inciden en las situaciones de exclusión, pero no el único ni necesariamente el principal, de forma que es posible ser pobre y no estar excluido, o estar excluido sin experimentar situaciones de pobreza (Subirats, 2004; SIIS Centro de Documentación y Estudios, 2013; Jiménez, Luengo y Taberner, 2009).

\section{Medidas tomadas ante el incremento de los desahucios}

Ante el incremento de desahucios, en 2009, un grupo de personas decidió crear una asociación en contra de que las familias perdiesen su casa y se quedasen en la calle con tal de "garantizar que los bancos cobren las deudas"2. Esta asociación es conocida como Plataforma de Afectados por la Hipoteca (PAH) y cuenta con 214 nodos en todo el Estado español. Trabaja en distintas campañas, como Stop Desahucios, Obra Social PAH, Dación en Pago e Îndice de Referencia de Préstamos Hipotecarios (IRPH).

Desde el ámbito legislativo, el 14 de mayo de 2013 se promulgó la Ley 1/2013 de Medidas para Reforzar la Protección a los Deudores Hipotecarios, Reestructuración de Deuda y Alquiler Social, dadas “las circunstancias excepcionales que atraviesa nuestro país, motivadas por la crisis económica y financiera, en las que numerosas personas que contrataron un préstamo hipotecario para la adquisición de su vivienda habitual se encuentran en dificultades para hacer frente a sus obligaciones" (preámbulo). En su primer artículo, se recogen ciertas situaciones

${ }^{2}$ Autodefinición recogida en la página web de la Plataforma de Afectados por la Hipoteca («http://pahaltpenedes.blogspot.com. es/p/presentacion-pah-alt-penedes.html $)$. en las que, durante un plazo de dos años desde la entrada en vigor de la Ley, se suspenderían todos los lanzamientos de viviendas habituales de colectivos especialmente vulnerables, entre ellas, familias con hijas e hijos menores de tres años.

El Gobierno Vasco, a través del Departamento de Justicia y Administración Pública Vasca, puso a marcha un nuevo servicio de mediación hipotecaria, enmarcado en los servicios de cooperación con la Justicia (Etxebide, 2011). En su informe anual de 2013 al Parlamento, el Ararteko informó de que había comenzado una investigación de oficio respecto al Servicio de Ayuda al Sobreendeudamiento Familiar del Gobierno Vasco (Ararteko, 2013b).

\section{Derechos de la infancia y desahucios}

Según el artículo 39.4 de la Constitución española, las niñas y los niños gozarán de la protección prevista en los acuerdos internacionales que velan por sus derechos. En el ámbito de la protección de la infancia, España firmó y ratificó la Convención sobre los Derechos del Niño de 1989 de Naciones Unidas, por lo que la legislación vigente española, en lo referido la protección de la infancia, está regulada según lo dispuesto en dicho tratado.

La Convención es el tratado internacional de derechos humanos que más ratificaciones ha recibido (con la adhesión de todos los países del mundo, excepto de Estados Unidos y Sudán del Sur). Se reconoce como el instrumento internacional de promoción y protección de los derechos de los niños, niñas y adolescentes más completo, dado que articula los derechos civiles, políticos, económicos, sociales y culturales (Verhellen, 2002) de las personas menores de 18 años (Casas, 1998). Ha supuesto un cambio de paradigma dentro de la consideración de la infancia, que ha pasado de considerarse un objeto de protección a un sujeto de derechos (Qvortrup, 1992; Casas, 1998; Gaitán, 2006; Dávila y Naya, 2010; Campoy, 1998; Cardona, 2012; Verhellen, 2002; Compte Nunes, 2015).

Siguiendo las observaciones del Comité de los Derechos del Niño, la Convención incluye cuatro artículos que vertebran todo el texto y que son un buen referente para analizar el cumplimiento de todos los demás derechos reconocidos en este tratado: la no discriminación, el interés superior del niño, la supervivencia y el desarrollo infantil, y el derecho a la opinión (Dávila y Naya, 2011). En la Figura 1 se resumen los cuatro artículos que son los principios básicos de la Convención.

Al haber ratificado el Estado español la Convención, proteger a la infancia y dar cumplimiento a sus derechos ya no es una opción, sino una obligación que se ha comprometido a cumplir (Casas, 1998; Cardona, 2012; Cárdenas Miranda, 2011), y debe entender su carácter indivisible e interdependiente (Dávila y Naya, 2011). 


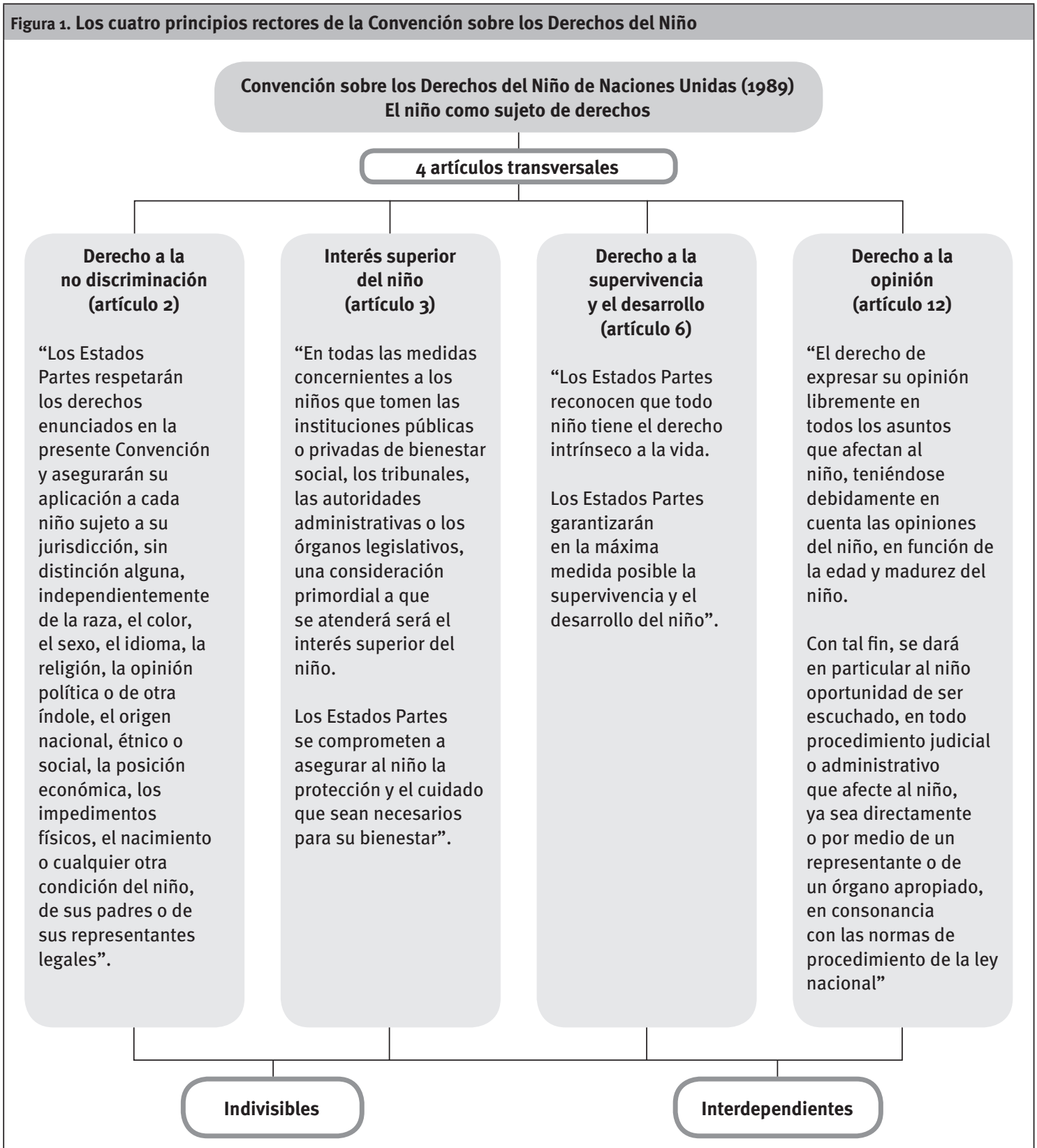

Fuente: Elaboración propia a partir de Unicef Comité Español (2006).

Aunque el carácter vinculante de la Convención es incuestionable, pocas han sido las sentencias emitidas basadas en ella o referidas a la infancia en los procesos de desahucio y que afecten al Estado español. Cabe mencionar la sentencia del Tribunal Europeo de Derechos Humanos de 2013 que detuvo la ejecución de un desahucio de más de una decena de familias que vivían en un bloque ocupado en Girona, conocido como el Bloque del Salt. En la sentencia se alude a la vulneración de los derechos de las personas y, especialmente, de los de las niñas y niños si ese desalojo se produjese. Los derechos objeto de vulneración eran el artículo 3 y el artículo 8 del Convenio de los Derechos Humanos, prohibición de la tortura y derecho al respeto a la vida privada y familiar, respectivamente. Asimismo, suspendía la orden de desahucio hasta que las autoridades españolas informaran sobre los acuer- dos adoptados para asegurar una vivienda adecuada y servicios sociales a los demandantes. Así se recoge en la sentencia de la demanda $n^{0}$ 62388/13 dictada por Tribunal de Derechos Humanos:

¿Cuáles son las medidas que las autoridades nacionales se proponen adoptar en relación con los demandantes, particularmente los niños, atendiendo a su vulnerabilidad para prevenir la alegada vulneración del artículo 3 y 8 del Convenio? En especial, ¿cuáles son las medidas relacionadas con el alojamiento y la asistencia social que van a adoptar las autoridades nacionales?3

\footnotetext{
3 Traducción propia.
} 
Haciéndonos eco de las sentencias españolas, aunque no hemos conseguido la sentencia original, la jueza Lourdes Menéndez González-Palenzuela, paralizó el desalojo de una mujer y sus tres hijos hasta que los chicos terminaran el curso escolar y hasta que la Comunidad de Madrid les garantizase una vivienda digna, basándose en el interés superior del niño (Agencia Efe, 2013).

\section{Objetivos y método}

El propósito general de este artículo es mostrar la realidad de la infancia inmersa en este fenómeno de pérdida de vivienda desde un análisis de la Convención sobre los Derechos del Niño. Este artículo aporta algunos de los resultados de la investigación titulada "Los derechos de las niñas, niños y adolescentes en situación de desahucio. El caso de Gipuzkoa", que se llevó a cabo durante el curso académico 2013-2014 en la Universidad del País Vasco/Euskal Herriko Unibertsitatea (UPV/EHU). En ella se siguió un diseño flexible, con el que se trató de comprender, y no de obtener meros datos estadísticos (Blaxter, Hughes y Tight, 2008) del fenómeno de los desahucios y de la infancia afectada. La representatividad no fue uno de los objetivos, porque, como bien indica Álvarez-Gayou (2003), una investigación puede ser valiosa si se realiza en un solo caso, en una familia 0 en un grupo cualquiera de pocas personas. Apostamos por conocer, describir e interpretar la realidad de las niñas y niños inmersos en las situaciones de desahucio en distintas voces, incluida la de la infancia, todas ellas dentro de su marco de referencia (Taylor y Bodgan, 1986). La recogida de la información se llevó a cabo mediante entrevistas en profundidad y entrevistas semiestructuradas.

\subsection{Participantes}

Como se puede ver en el Cuadro 1, seis fueron las voces de esta investigación, voces, que a su vez, ofrecieron tres perspectivas: familiar, jurídico-legislativa y de protección a la infancia. Los datos de contacto de las familias y profesionales que se ajustaban a nuestros criterios de inclusión y exclusión se consiguieron a través de miembros que conocíamos de la Plataforma de Afectados por la Hipoteca. Los criterios de inclusión fueron que el desahucio debía haberse producido a consecuencia de la pérdida de empleo y que la persona afectada tuviera un mínimo de dos años de experiencia laboral en su ámbito profesional. Fue criterio de exclusión la inexistencia de cualquier tipo de intervención familiar a causa de una posible situación de riesgo o desamparo de las niñas y niños hasta comenzar los problemas de impago con la entidad financiera ${ }^{4}$.

\begin{tabular}{|c|c|c|c|}
\hline Perspectiva & Técnica utilizada & Participantes & Características \\
\hline \multirow{3}{*}{ Familiar } & \multirow{3}{*}{$\begin{array}{l}\text { Entrevista en } \\
\text { profundidad }\end{array}$} & $\begin{array}{l}\text { Madre } 1 \text { (madre de la menor } \\
\text { entrevistada). Nos referiremos a } \\
\text { ella como Marta }\end{array}$ & $\begin{array}{l}\text { - Residente en: Euskadi. } \\
\text { - Edad: } 34 \text { años. } \\
\text { - Nacionalidad: española. } \\
\text { - Situación laboral: desempleo. } \\
\text { - Motivo de la suspensión temporal del desahucio: } \\
\text { carencia de dos años con la entidad financiera. } \\
\text { - Tipo de familia: nuclear con un hijo de } 9 \text { y una hija de } \\
13 \text { años. }\end{array}$ \\
\hline & & $\begin{array}{l}\text { Madre 2. Nos referiremos a ella } \\
\text { como Lourdes. }\end{array}$ & $\begin{array}{l}\text { - Residente en: Euskadi. } \\
\text { - Edad: } 35 \text { años. } \\
\text { - Nacionalidad: española. } \\
\text { - Situación laboral: desempleo. } \\
\text { Motivo de la suspensión temporal del desahucio: } \\
\text { amparo en la Ley } 1 / 2013 \text {. } \\
\text { - Tipo de familia: monomarental, aunque en el momento } \\
\text { de la entrevista convivía con ella y su hija de } 16 \text { años } \\
\text { su nueva pareja. }\end{array}$ \\
\hline & & $\begin{array}{l}\text { Adolescente (hija de Marta). Nos } \\
\text { referiremos a ella como Andrea. }\end{array}$ & $\begin{array}{l}\text { - Residente en: Euskadi. } \\
\text { - Edad: } 14 \text { años. } \\
\text { - Nacionalidad: española. } \\
\text { - Estudios: } 3^{0} \text { ESO. }\end{array}$ \\
\hline \multirow{2}{*}{ Jurídico-legislativa } & \multirow{2}{*}{$\begin{array}{l}\text { Entrevista } \\
\text { semiestructurada }\end{array}$} & Abogado de la PAH & $\begin{array}{l}\text { - Experiencia laboral: dos años en el ámbito de los } \\
\text { desahucios. }\end{array}$ \\
\hline & & Abogada de la PAH & $\begin{array}{l}\text { - Experiencia laboral: cinco años en el ámbito de los } \\
\text { desahucios. }\end{array}$ \\
\hline $\begin{array}{l}\text { Ámbito de la } \\
\text { protección a la } \\
\text { infancia }\end{array}$ & $\begin{array}{l}\text { Entrevista } \\
\text { semiestructurada }\end{array}$ & $\begin{array}{l}\text { Trabajadora social, trabaja } \\
\text { como técnica en el ámbito de } \\
\text { la protección a la infancia de la } \\
\text { Diputación Foral de Gipuzkoa }\end{array}$ & $\begin{array}{l}\text { - Experiencia laboral: diez años en el ámbito de la } \\
\text { protección a la infancia. }\end{array}$ \\
\hline
\end{tabular}

PAH: Plataforma Anti Desahucios.

Fuente: Elaboración propia.

${ }^{4}$ El motivo de incluir este criterio fue el análisis del derecho a la unidad familiar (artículo 9 de la Convención sobre los Derechos del Niño) que realizamos en la investigación en la que se basa este artículo. 


\section{Análisis de la información}

El análisis de las entrevistas se realizó con un sistema de categorización mediante un método deductivo-inductivo, esto es, partimos de unas categorías amplias definidas a priori, basadas en nuestro marco teórico, a partir de las cuales fuimos introduciendo modificaciones y ampliaciones, lo que nos permitió adaptarlo al conjunto de datos extraídos del trabajo de campo. En el Cuadro 2 se recogen algunas de las dimensiones de análisis y sus correspondientes categorías, que se ajustan a la parte de la investigación que se presenta en este artículo.

\begin{tabular}{|c|c|}
\hline \multicolumn{2}{|c|}{ Cuadro 2. Dimensiones de análisis y categorías } \\
\hline \multicolumn{2}{|c|}{ La infancia y sus derechos en los desahucios en Gipuzkoa } \\
\hline Dimensiones de análisis & Categorías \\
\hline \multirow{2}{*}{$\begin{array}{l}\text { Características de las } \\
\text { personas afectadas por un } \\
\text { desahucio }\end{array}$} & $\begin{array}{l}\text { Representación social de la vivienda } \\
\text { en propiedad }\end{array}$ \\
\hline & $\begin{array}{l}\text { Cambio en los perfiles de las } \\
\text { personas afectadas }\end{array}$ \\
\hline \multirow{3}{*}{$\begin{array}{l}\text { Cambios en el entorno } \\
\text { familiar y en la infancia }\end{array}$} & Ámbito emocional \\
\hline & Ámbito relacional \\
\hline & Ámbito escolar \\
\hline \multirow{4}{*}{$\begin{array}{l}\text { Lectura de la Convención } \\
\text { sobre los Derechos del } \\
\text { Niño en los casos de } \\
\text { desahucio }\end{array}$} & No discriminación \\
\hline & Interés superior del niño \\
\hline & $\begin{array}{l}\text { Derecho a la vida, el desarrollo y la } \\
\text { supervivencia }\end{array}$ \\
\hline & Derecho a la opinión \\
\hline \multirow{2}{*}{$\begin{array}{l}\text { Prejuicios y exclusión } \\
\text { social }\end{array}$} & Prejuicios \\
\hline & Exclusión social \\
\hline
\end{tabular}

Fuente: Elaboración propia.

\section{Resultados e interpretación de los datos}

Aunque en este artículo vayamos a realizar una lectura sobre los derechos transversales de la infancia en situación de desahucio, debemos también exponer en este apartado otros resultados que han surgido en el trascurso del trabajo de campo y que ayudan a contextualizar ese fenómeno.

\subsection{Características de las personas afectadas por un desahucio}

\subsubsection{Representación social de la vivienda en propiedad}

En todas las entrevistas se alude a que la adquisición de una vivienda en propiedad se trataba de una necesidad real. Esta concepción se soporta sobre un tipo de mentalidad muy habitual en nuestra sociedad, que es la de ser propietaria o propietario. Como explicaba Marta, adquirir una vivienda en propiedad era "conseguir el sueño de tu vida [...], tu mente dice: 'pues en vez de pagar un alquiler, que ese dinero va a la basura, prefiero invertir en algo que, a futuro, si yo puedo permitirlo, será para mí”.

\subsubsection{Cambio en los perfiles de las personas afectadas}

En el caso de nuestras participantes 5 , el desempleo era la causa por la que no habían podido hacer frente al pago de las cuotas del préstamo que habían adquirido con la entidad financiera. No obstante, a lo largo de las entrevistas se pudo constatar cómo las causas y los perfiles de las personas afectadas por estas situaciones estaban cambiando. Al principio, el desempleo había afectado a las familias más vulnerables y ahora estaba afectando a las clases medias, a autónomos, fiadores, avalistas, pequeños empresarios y, en especial, a las mujeres divorciadas que se habían quedado con el domicilio familiar. Como explicaba el abogado:

Hay un grupo particular de gente que está viviendo esto con especial crueldad. En los divorcios donde a la madre [...] se ha adjudicado [...] la custodia de los menores, y la sentencia de divorcio dice que la hipoteca ha de ser pagada, o por ejemplo, al $50 \%$ entre los progenitores, el padre pagará el $50 \%$, la madre pagará el 50\%, o bueno u otros porcentajes [...]. ¿Entonces, qué ocurre? Que la madre, aunque con sus recursos, su trabajo, pague su parte de hipoteca, hay una parte que igual el padre no la paga.

\subsection{Cambios en el entorno familiar y en la infancia}

\subsection{1. Ámbito emocional}

\section{a) Sentimientos de culpabilidad y vergüenza}

En los testimonios se puede apreciar cómo, desde el momento en que se tenía conocimiento de un posible desahucio, aparecían los sentimientos de culpabilidad y de vergüenza. Como exponía Marta:

Lo primero que piensas es que has metido la pata, que la has cagado, [...] ‘ilo que he hecho! ¡Ahora no puedo pagar!' Lo primero [...] que te viene a la mente es la culpa, de sentirse mal por no poder pagar la hipoteca [...] [, pero también por] no poder tener algo para dar de comer a tus hijos, pues es duro, [y encima] ique yo tenga que venir a mendigar comida a Cáritas!

\section{b) Cambios de actitud}

También queda constancia de que los sentimientos de culpabilidad y vergüenza de los padres y las madres afectaban a su salud, con episodios de depresión, cambios de humor, irascibilidad o cansancio. Marta decía que:

Llegó un momento que yo no tenía ni fuerzas para ir a jugar [...], pero luego me sentía mala madre,

5 Utilizaremos el femenino genérico para referirnos a las mujeres $\mathrm{y}$ al hombre que participaron en el estudio. 
porque no estoy jugando con ellos, les estoy arrastrando a mi tristeza o a mi sufrimiento [...]. Llega un momento que te cansas de luchar, luchar, luchar, y bueno..., simplemente por intentar sobrevivir.

Por su parte, Lourdes admitía que pasó por una “depresión muy gorda".

La primera actuación de los padres y de las madres respecto a sus hijas e hijos era la de esconder la situación que estaban viviendo. No obstante, la percibían. Como relataba Andrea: "cuando tenían que hablar, siempre me decían: “iAndrea, vete a jugar con tu hermano a la habitación!”. Aunque se tratase de esconder la situación, la infancia lo percibía y comenzaba a manifestarse de un modo distinto en los diferentes ámbitos donde interactuaba, e incluso su estado de ánimo se veía alterado. Como explicaba Andrea, su hermano, "de repente se echa a llorar, de repente se echa a reír...”. A su vez, también comentaba que su hermano se seguía poniendo muy nervioso cuando su padre le chillaba, lo que originaba que se le olvidasen las cosas.

La abogada indicaba que "en el momento que más o menos perciba lo que va a ocurrir, o lo sepa, porque se lo han dicho, si una persona adulta puede vivir esa situación como un auténtico infierno, pues para un niño, es que se le cae todo el mundo, la armonía, su casa, su familia, su mundo, su mundo... Entonces, claro, ¿cómo reacciona un niño ante eso? [...] Con un sentimiento de vergüenza, entre la rabia, la pena...".

En las entrevistas se pudo recoger que el hijo y la hija de Marta acudieron a unos "ciclos orientativos" que les ayudaban a hablar sobre lo que estaba sucediendo en su casa. La abogada señalaba que era habitual que los niños y niñas de familias acudieran a tratamiento psicológico.

\section{c) Miedo a perder la custodia}

La preocupación por la intervención de los servicios sociales y la Diputación Foral de Gipuzkoa ante la separación de la unidad familiar, y por la suspensión temporal o definitiva de la custodia es algo que las dos madres admitían sentir, y la abogada consideraba como una preocupación añadida. A Marta se la tranquilizó al respecto, puesto que, como le había explicado su médica, las intervenciones sólo se producirían si fuese "una mala madre", "una madre que no se preocupe por sus hijos".

La preocupación de Lourdes tenía otro motivo, ya que había sufrido amenazas en uno de los tres intentos de lanzamiento de su vivienda que había experimentado. En una de ellas, como relataba, le advirtieron: "no sé si has vaciado o no el piso, y no sé si tienes menores o no en el domicilio, pero en ese caso tendrá que venir Diputación a hacerse cargo de él". Añadió que, tras el cambio a una actitud rebelde de su hija, el colegio también la había amenazado con llamar a servicios sociales de base, a los que acudió, y la solución que le ofrecieron, según su testimonio, fue:

Que mi pareja actual se fuese a una casa vieja, que es una ruina que tiene su abuela en Portugal, que yo me fuera a vivir a un trastero que tiene mi hermano en una vivienda de protección ilegal (sic) y claro, como es un trastero y no una vivienda particular, pues te quitarían la custodia de la niña y se encargaría Diputación de ella.

A la abogada también le constaban estas amenazas. La trabajadora social, por su parte, consideraba la vivienda como un recurso material importante de la infancia y afirmaba que le constaba que se ayuda "a la familia para solventar esos problemas y dar tanto ayuda económica como estructural para solventarlo". Además, se posicionaba en contra de intervenir en los casos donde faltaban recursos económicos y de desahucio. Aseguraba que "no se toma una medida de protección sólo y meramente por causas económicas o de desahucio", siempre que no sea una situación prolongada, esto es, "cuando efectivamente se ve que, bueno, que es verdad, que igual, dado a soluciones 0 a decisiones inadecuadas, pues los niños correrán un riesgo elevado de malestar, pues bueno, ahí sí se actúa", pero aseguraba que "son varios factores que se tienen que unir, no sólo la falta de recursos económicos".

\subsection{2. Ámbito relacional}

\section{a) Aumento de violencia intrafamiliar}

De los testimonios se puede extraer que el comienzo de la dinámica de impago trajo consigo un incremento de las discusiones en la familia, como explicaba Andrea en su entrevista:

Una vez hubo una discusión muy fuerte y entonces el aita [mi padre] pues se fue, hizo la maleta y se fue, ahí pues sí tuve miedo de que mis aitas [mis padres] se separaran [...], pues como mi ama [mi madre] tenía que pagar todo eso, porque mi aita no estaba bien, o yo qué sé..., que a mi aita se le cruzara un cable e hiciera cualquier chorrada.

En el caso de Lourdes, decía que su hija, en un principio, sentía frustración y vergüenza por la situación en la que se encontraban, sentimientos que mostraba con reproches hacia la madre y llegando "a las manos".

\section{b) Mantenimiento de los roles de género}

En los resultados se puede observar cómo la lucha por salir de esa falta de recursos y el desahucio, enlazada con las responsabilidades familiares, se repartía de manera desigual entre los hombres y las mujeres. Marta no identificaba esa lucha como feminismo o machismo, sino que "la mujer es la que toma 
la iniciativa de decir: ‘jvamos!'. Porque yo creo que el hombre, en ese aspecto, siente más vergüenza”. Proseguía justificando que "ellos ven más la forma de luchar en el trabajo, buscar trabajo..., o... buscar de otro tipo, ¿no?... Derivan más esa responsabilidad a la mujer”. Andrea afirmaba que: "mi ama se movía, iba a todos esos sitios, y mi aita no hacía nada por levantarse, por ayudar a la ama". El abogado añadía que la lucha entre el hombre y la mujer era distinta, haciendo referencia a los roles de género, a la realidad en la que vivimos:

El padre, porque es el que se siente culpable de su orgullo, es el león que no ha sabido mantener la manada, es un mal león, es un mal león, porque todos los demás han conseguido, por lo menos, mantener a su familia, porque el hombre es protector" [, y] ella busca soluciones va a Stop [Desahucios], a Cáritas, o a trabajar de puta, lo que haga falta, y él se ahorca y le deja el muerto a ella encima, pero se ahorcan ellos. [...] Ellas dan la vida y ellos tiran la suya.

\section{c) Cambio de círculo de amistades}

El cambio de círculo de amistades en la infancia también es visible en las entrevistas. Lourdes explicaba que su hija había cambiado tres veces de círculo de amistades tras empezar el problema del desahucio. A su vez, Marta y Andrea también aludían a este cambio de amistades. El nuevo círculo de amistades de las participantes era definido por todas ellas como una "mala influencia", hasta el punto de tomar la decisión de un cambio escolar. Como explicaba Lourdes, "se empezó a juntar con otra gente más marginal, digo marginal porque ya son extremos, gente que no iba al colegio, que estaban sin escolarizar".

Este cambio de amistades se reflejó en la disciplina y en la actitud de la infancia, con ejemplos como empezar a faltar al colegio, robar dinero, o "meterse en follones". Andrea admitía que algunas actuaciones habían estado influenciadas por las nuevas amistades, pero que "no sabía cómo decirle que no..., o era como un miedo a que me hiciera cualquier cosa".

\subsection{3. Ámbito escolar}

Los resultados muestran que, en el momento en el que las niñas y los niños percibieron lo que estaba sucediendo, su rendimiento escolar comenzó a empeorar. Como señalaba la trabajadora social, "cuando ve que en casa falta dinero, que los padres están nerviosos porque no hay dinero, que la comida que hay escasea completamente, muchas veces incluso nutricionalmente no estás bien, es más fácil que caigas enfermo y todo, y que estés más desatento y más cansado en clase y no tengas ganas de jugar, pues evidentemente influye de una manera totalmente negativa", tanto, que su comportamiento en el colegio se vio alterado, con manifestaciones de rebeldía, descenso de su rendimiento escolar o incluso dejando el colegio, como la hija de Lourdes. En el caso de Andrea, pasó de no suspender ninguna asignatura a suspender siete. Su hermano también empeoró su rendimiento en la escuela.

Resumiendo los resultados expuestos hasta ahora, cuando las familias de nuestra muestra comenzaron a tener problemas económicos por la pérdida de sus trabajos, empezaron a no poder hacer frente a la cuota del préstamo que tenían con su entidad bancaria, entrando en una dinámica de impago que abocaba al desahucio. La falta de recursos económicos y el futuro desahucio ocasionaron cambios en los sentimientos y en las actitudes de las y los miembros familiares en el ámbito doméstico y, en el caso de la infancia, también en el escolar y el relacional. A esto hay que sumarle el miedo que las madres llegaron a sentir ante una hipotética intervención de la Diputación Foral de Gipuzkoa.

\subsection{Lectura de la Convención sobre los Derechos del Niño en los casos de desahucio}

Observando ahora los desahucios desde la perspectiva de la Convención, se puede apreciar cómo distintas acciones o decisiones podrían atentar directamente contra los cuatro derechos transversales del texto: la no discriminación; el interés superior del niño; el derecho a la vida, la supervivencia y el desarrollo; y el derecho a la opinión. Estos cuatro derechos son los que el Comité sobre los Derechos del Niño considera referentes para analizar el cumplimiento de los demás, dada su interdependencia e indivisibilidad (Dávila y Naya, 2010).

\subsubsection{Derecho a la no discriminación}

Acorde con el artículo 2 de la Convención (Figura 1), las niñas y los niños no pueden ser discriminados por ninguna causa. La discriminación hacia la infancia en los casos de desahucio analizados se muestra respecto a la Ley $1 / 2013$ y respecto al círculo de amistades de la infancia.

Por una parte, la citada ley suspende el desahucio de familias con ciertas características en un plazo de dos años desde su promulgación. Como afirmaban nuestras juristas, no es nada fácil cumplir las condiciones para ello, ya que "lo consigue quien está en la más absoluta miseria”. En el caso de nuestras familias, la primera, formada por Marta y Andrea, consiguió una carencia de dos años con la entidad financiera, y la segunda, encabezada por Lourdes, acababa de conseguirlo, aunque todavía la entidad se lo discutía. Las características que cumplía Lourdes eran no tener avalista, no ganar lo suficiente y que la tasación de su casa de protección oficial no superaba los 120.000 euros.

Cuando les preguntamos a las juristas, nos explicaron que la Ley 1/2013 se había creado para situacio- 
nes de especial vulnerabilidad en las que entraban niñas y niños, pero sólo se contemplaba la especial vulnerabilidad de los menores de tres años. Tanto Lourdes como las juristas afirmaban que esta ley no daba solución a la infancia en su totalidad. El abogado hablaba de la ineficacia de la ley en estos términos: "Entonces, [si tiene] 3 años y 1 día ese [niño] ya no es vulnerable, [y si tiene] 2 años y 9 meses, ése es vulnerable. Es una idiotez, hablar de vulnerabilidades y luego buscar la aritmética de los números..., o sea, me parece ridículo".

Por otro lado, la discriminación no sólo muestra una faceta legislativa, sino también relacional. Marta creía que el cambio de amistades de su hija se debía a que "igual ella no encuentra, no encaja” y se comienza a juntar con un nuevo grupo de amistades, "con niños, pues, que vienen de familias desestructuradas". Su hija, en cambio, nos contaba otra realidad:

Me acuerdo [de] que una vez mis aitas estaban hablando [...] con mi tutora unas cosas, y había unas de mi cuadrilla en un banco que estaba al lado de donde ellos estaban hablando, en la ventana, y la ventana estaba abierta y [...] escucharon todo lo que estaban hablando, y luego fueron y se lo contaron a todos los de mi cuadrilla, pero inventándose cosas que no eran verdad. Y entonces, mi cuadrilla era como así, un poco de ricos, y pues no sé [...], al ver que yo no tenía el mismo dinero que ellos y así [...], pues me dejaron sola.

Lourdes también contemplaba algo parecido respecto a su hija, ya que "cuando empezamos nosotros a tener los problemas con el banco [...], son como un poco clasistas, gente pudiente y estas cosas, que los niños son muy crueles. Y es cuando ella decidió romper con ellos, se sintió herida, se sintió dolida".

En los tres testimonios se puede apreciar el cambio de amistades desde que comenzaron los problemas económicos y con la entidad financiera. Observamos un comportamiento cruel en el grupo de amistades cuando apartaron y dejaron solas a estas niñas sin dinero. Tras romper con el círculo de amistades, se unieron a otro por la simple razón de ser los primeros en acercarse, aunque la influencia de éstos y éstas no fuese buena, como bien reconoció Andrea.

Aunque no es una discriminación en sentido estricto, los resultados muestran cómo la falta de recursos revierte directamente en la disminución de dinero o paga, y en la oportunidad de realizar actividades lúdicas y extraescolares junto con otras niñas y otros niños. Actividades como ir al parque, al cine, a clases de inglés, de danza o a cualquier actividad que tenga que ver con el entretenimiento o la formación extraescolar significativa en su desarrollo se vieron totalmente condicionadas. Andrea comprendía que no podía hacer lo mismo que sus compañeras de clase. Le encantaría ir a clases de baile, pero en su casa hace falta ese dinero, que se destina a cosas más importantes, como comer.
Los testimonios dejan constancia de que cuando comenzaban los problemas económicos, los recortes fueron inevitables, prescindiéndose incluso del suministro de luz. Como exponía el abogado, "con una deuda de 200.000 , tu vida es otra: olvídate de la clases de inglés, olvídate del gimnasio y olvídate de los libros y olvídate de un montón de cosas, porque tus padres no tienen".

\subsubsection{Interés superior del niño}

El interés superior del niño se refiere a la consideración primordial en todas las medidas concernientes a las niñas y niños que tomen distintas instancias 0 agentes (Figura 1). Si observamos detalladamente este artículo de la Convención, nos podremos dar cuenta que se refiere a todas las decisiones y actuaciones que se realicen sobre la infancia. En los casos analizados, hay que decir que más bien se echó en falta la consideración primordial de los intereses de la infancia de cualquier institución, o incluso de la propia sociedad.

El Ministerio Fiscal tiene, entre otras competencias, la de velar por los intereses y derechos de la infancia (Ley $15 / 2015$, art. 4), pero hasta la fecha de la realización de las entrevistas, como indicaron las juristas participantes, no había hecho aparición, sea por desconocimiento, como constataba la abogada, o por no tener herramientas, como explicaba el abogado: "ese fiscal que estaba en el divorcio ha desaparecido en el momento del desahucio, no está, no hay nadie”. Las abogadas relataban que habían solicitado, en un procedimiento judicial, la presencia del fiscal, pero la respuesta de la jueza fue negativa, por contemplar que “para proteger al menor ya está su madre”. En la práctica, ninguna madre ni representante legal puede oponerse a un procedimiento judicial de ejecución hipotecaria por el hecho de que la vivienda sea un interés y un derecho para sus hijas e hijos menores de 18 años, ni tampoco existen herramientas para ello. La única posibilidad de oponerse a estos procedimientos judiciales es la existencia de cláusulas abusivas en el contrato del préstamo hipotecario.

Las entidades financieras, por su parte, no contemplaban el interés superior del niño a la hora de tomar decisiones, como explicaba Marta: "lo único que les vale son las cifras, y lo que ganas. Lo que percibes. Ellos no escuchan ni si tienes recibos de agua pendiente, ni si no tienes para comer, ni si tienes hijos o no". Esta falta de consideración es denunciada en la entrevista por la abogada, que aceptaba que la vivienda pasase a ser del banco, que se inscribiese en el registro como del banco, pero reclamaba que, al haber menores viviendo en ella, aquél no pidiese el lanzamiento de la vivienda para dejarla cerrada.

En los discursos de nuestras participantes, aparece la falta de consideración de la sociedad respecto a la infancia y a su interés superior. Siendo la Iglesia también una institución a la que acude parte de la sociedad, el abogado denunciaba la inexistente actuación 
del episcopado español para proteger el interés de la familia y de la infancia de tener un techo:

El episcopado español saca a millones de personas a la calle a protestar contra los matrimonios homosexuales, porque ellos están por la familia. Es muy bonito hablar de la familia [...], pero la familia necesita un techo [...], entonces ese recinto se tiene que garantizar; si no hay techo, no hay nada [...].

\subsubsection{Derecho a la vida, la supervivencia y el desarrollo}

Los resultados reflejan cómo las familias hacían lo que fuese necesario para poder pagar primero el préstamo, y después hacían los números pertinentes para ir afrontando el resto de los gastos. La abogada señalaba que, tras haber estado en distintas casas con familias que estaban en estas situaciones, la realidad era la siguiente:

Si te tienes que estar comiendo macarrones todo el mes, porque no te llega para nada más..., la hipoteca [...]. Hemos acudido [...] a viviendas donde no hay luz, y es que esa gente prefiere pagar la hipoteca que tener luz o calefacción; no se gasta en calefacción, se gasta muy poquito en comer, no se compra nada de ropa, y entonces, se dejan de pagar los recibos de la luz y del gas, en muchos, muchos casos para pagar la hipoteca [...], porque dejar de pagar la hipoteca es quedarte sin casa; por eso piensas que mejor tener una casa sin luz [...] que quedarte sin casa.

Corroborando las palabras de la abogada, Marta reconocía haberse sentido mal por no tener nada que dar de comer a su familia, verse en la necesidad de que su hijo e hija fuesen al comedor escolar, ya que ésta era una manera de garantizar que iban a comer, e incluso decir "pues mira, no te puedo comprar hoy esas playeras, o no te puedo comprar este niqui, o... no te puedo comprar simplemente algo tan básico como unas bragas y un sujetador". Ante esa situación, tuvo que acudir a Cáritas, donde reconoció sentir que mendigaba comida. Lourdes coincidió con lo expuesto por la abogada y por Marta en cuanto a la administración de la economía familiar. Explicaba que su hija y ella no habían pasado hambre, puesto que siempre "hay algún amigo que te da o que te presta un tupper", y si no, en esas situaciones, "tú te haces las cruces, y dices 'pues yo no como', y haces lo que sea para ella [refiriéndose a su hija], y ya está”.

Siendo las ayudas sociales una fuente de ingresos para algunas familias vascas y españolas, preguntamos a las participantes sobre si habían acudido a los servicios sociales de base en busca de ayudas, y si habían accedido a ellas, de qué tipo eran. En cuanto a ayudas económicas de los servicios sociales por encontrarse ante un posible desahucio, y tras poner en la mesa todos los papeles e informes de la familia,
Marta afirmó no haber recibido ninguna, puesto que, como le dijeron en los servicios sociales, al tener un piso en propiedad, no podía percibir ninguna ayuda económica, a lo que ella respondió: “‘¿tengo que estar desahuciada o vivir debajo de puente para recibir ayudas?', y me contestaron que sí [...]. La única ayuda que pude percibir es de Cáritas". Por medio de la pediatra, accedió también a unos "ciclos orientativos" donde profesionales les proporcionaron asistencia pedagógica y psicológica para afrontar la situación que estaban viviendo y que, como expresaba Andrea, son "para ayudar a los jóvenes que tienen problemas, y hacemos juegos, o hacemos funciones". La experiencia de Lourdes no se diferencia demasiado en cuanto a las ayudas percibidas, aunque en este caso, los servicios sociales, aparte de la Justicia gratuita que le correspondía, le ofrecieron un piso de emergencia social durante dos meses. Es de mencionar que, como bien apuntaba la abogada, las ayudas se dan en función de rentas anteriores, como la justicia gratuita, por lo que mucha gente no puede acceder ellas, dado que su situación difiere absolutamente de la anterior.

Las dos familias entrevistadas recibieron ayuda de Cáritas. El servicio de Cáritas funciona de manera diferente en los distintos municipios; de hecho, en el de Lourdes no había Cáritas, por lo que tenían que ir al de al lado, al cual definió como "clandestino". En el municipio de Marta, sólo podían acudir a Cáritas una vez al mes, cuando Lourdes acudía cada 15 días. En cuanto a los productos que allí se repartían, Marta decía que:

Nosotros somos cuatro, nos suelen dar seis briks de leche, una botella de aceite, una [docena] de huevos y casi todos los productos -que es triste, pero claro...-, la mayoría están caducados o a punto de caducar. Lo que pasa es que hay cosas que sabes que las puedes comer y otras que te da miedo consumirlas y las tiras directamente.

Tanto Marta como Lourdes se quejaban de la escasez de los productos obtenidos en Cáritas, ya que Marta afirmó que sólo le duraban una semana, y Lourdes, "pues es un poco imposible llegar así ni a los dos días siguientes”. Sin embargo, la ayuda ofrecida allí no se limitó a recoger alimentos, sino que a Lourdes se le facilitó dinero para poder pagar un recibo de luz.

Como decía la trabajadora social, las ayudas sociales que existían en aquel momento eran pocas y el número de demandantes era mayor. Además, aseguraba que cada vez estaban más controladas y supervisadas:

[Las ayudas eran] para subsistir, y en muchos casos, ni para eso, y desde luego no garantizan, no cubren las necesidades básicas [...]. Quizá te dan como para poder subsistir con otros apoyos externos, como el apoyo de la familia, como otras ayudas de amigos..., para sacarte la vida adelante durante un corto periodo de tiempo, pero luego, a la larga, no. 
Al que está invisible, que puede estar mucho peor que el de al lado, pues normalmente no se le atiende, pero en los servicios sociales, como en el colegio, recibe las ayudas el que da la nota.

Por la vergüenza, por el miedo al qué dirán, se muda, se cambia de comunidad o miente, y al final, muchas veces, para cuando llegan a los servicios sociales y llegan a pedir ayuda, es que la situación es totalmente crítica, crítica, está la gente al borde de la locura.

\subsubsection{Derecho a la opinión}

El derecho a la opinión, acorde con lo dispuesto en el artículo 12 de la Convención (Figura 1), supone que la infancia debe ser sujeto activo a la hora de pronunciarse, de opinar, de ser escuchada y tomada en cuenta en todas las cuestiones que le afecten. En el caso de Marta, al haber conseguido la demora, no pasó por juicio. En cambio, Lourdes, sólo decía: “no, ni siquiera la asistente social, ni siquiera desde la Diputación; es por la edad, y no por lo que está pasando ella; en ese sentido, no le han preguntado nada de nada".

Cuando les preguntamos a las abogadas, nos comentaron que "sí, se les escucha llorar cuando salen de casa [...]. No se escucha en ningún momento", que son juicios en los que "se discute en términos mercantiles no afectivos [y que] la afectividad no existe" en estos procesos. Nos explicaban que el juez o la jueza están más interesados por cuestiones formales y económicas, y menos por la situación de las niñas y los niños:

¿Se debe o no se debe? Se debe, bien, entonces, usted debe la hipoteca. ¿En cuánto se ha tasado la casa? En tanto. ¿Cuánto es, el $60 \%$ ? Tanto..., pues adjudicada la casa y queda por pagar tanto. ¿Qué más hay? ¿Fiadores? No... En esos términos, es un procedimiento meramente mercantil, comercial [...], en el que está la entidad, por un lado, como ejecutante, y luego está el ejecutable, con su abogado.

No podemos entender esta opinión sobre el comportamiento de los jueces y las juezas, pero parece ser una práctica bastante habitual.

\subsection{Prejuicios y exclusión social}

\subsubsection{Prejuicios}

En el análisis queda patente la percepción de las participantes sobre los prejuicios que tenía parte de la sociedad ante las personas que están en un proceso de desahucio, sean niñas y niños, o no. Lourdes y la abogada comentaban que los prejuicios eran mayores al principio de este fenómeno, aunque "todavía hay cuatro que viven en su burbuja y, como el otro día nos decía un señor por la calle: ‘¡Paga lo que debes!' y [...] 'iLa culpa era tuya, porque habías vivido por encima de tus posibilidades!' [...]. Te sentías como un bicho raro, como alguien marginado". Marta, apuntaba a que "hoy en día [...] jte miran por debajo (sic) del hombro! Y eso, a mayores como a niños". Además, explicaba cómo que se sentía "juzgada por la gente, como ‘iMira ésta, en esta situación y se toma un café!", aunque achacaba ese pensamiento a gente que nunca se había visto en esa tesitura.

La trabajadora social se acercaba más a la visión de Marta, al explicar que "es lo de siempre, cuando te toca a ti, es cuando tomas conciencia, es un poco hipócrita”. Aseguraba que "le da pena la verdad, que cada uno lo tenga que ver en su propia carne para darse cuenta, pero bueno..., somos así”.

\subsubsection{Exclusión social}

Para terminar este apartado de resultados, habría que destacar la gran dificultad con la que se encuentra una familia en situación de desahucio, ya que aun perdiendo la casa, sigue teniendo una deuda con la entidad financiera. La deuda hace que puedan embargar una parte de los ingresos que entran en la cuenta corriente, lo que dificulta poder empezar de nuevo tras una situación de desahucio. Como explicaba el abogado:

Tú quieres empezar una nueva vida y dices: [...] 'Voy a hacerme repartidor, me voy a coger una furgoneta en renting'. Tú vas al renting y, como estás marcado en un fichero de morosos, no tienes derecho a un renting, con lo cual no tienes furgoneta. 'Bueno, pues me alquilo un local para vender fruta'. No, es que en cuanto el dueño del local pida informes, como estás en [el listado de la] Asnef [la Asociación Nacional de Establecimientos Financieros de Crédito], donde están los morosos, pues no te va a alquilar el local. 'Entonces, quiero un teléfono para trabajar, un móvil'. No, es que no te va a dar móvil nadie, porque estás en [el listado de la] Asnef, por lo cual te metes en una dinámica en la cual tienes que pagar en ' $B$ ' [dinero negro]. Al pagar en ' $B$ ', no cotizas; al no cotizar, no tienes prestaciones sociales, porque no estás cotizando; al manejar todo en 'B', no puedes domiciliar cosas, no tienes derecho al ADSL -porque el ADSL no se puede pagar en cash [efectivo], hay que pagarlo domiciliando el recibo en una compañía telefónica-, pues tú no puedes hacerlo; el cole de los niños... y poco a poco que vas haciendo, te vas excluyendo, te vas excluyendo, eres un niño diferente [...], entonces, ¿cómo sales de ahí? Es imposible, o sea, no hay segunda oportunidad [...], porque aun perdiendo la vivienda, si tus padres se han ido a la calle con una deuda de $\mathbf{2 0 0 . 0 0 0 ,}$ tu vida es otra [...], porque tus padres no tienen, no empiezan de cero, empiezan de -200. Y eso no se puede levantar, no se puede levantar esa losa. [...], porque en España la gente no hipoteca su casa, hipoteca su vida, porque luego entrega su casa y sigue debiendo toda su vida, él, sus 
padres y todos los que están, hipotecan su vida. [...] Estás condenado, además estás condenado [...], a no estar en el sistema [...]. Entonces, ¿qué soy?, un excluido social, y ésta es una de las cosas que tiene que ver con la exclusión social, el poder empezar una segunda oportunidad de cero.

\section{Conclusiones}

Como apuntábamos al comienzo de este artículo, el proceso de desahucio es un drama que vive parte de nuestra sociedad. El desahucio en sí no es más que la culminación de un proceso largo y sufrido que afecta a distintos ámbitos de la vida de la infancia. Se ha podido ver en los resultados cómo la falta de recursos económicos y la ausencia de ayudas sociales, la imposibilidad de pago a la entidad financiera y los recortes en los gastos domésticos han hecho que la familia al completo, y en este caso, la infancia, viese alterado su ritmo de vida, de estudios, de ocio.

La imposibilidad de hacer frente a la hipoteca es un efecto dominó que no sólo afecta a la pérdida de la vivienda, sino que se refleja en el estado de ánimo, en las actitudes, en las relaciones familiares y extrafamiliares, así como en los círculos de amistades de la infancia y la familia. Sabemos que la pobreza no es el único factor que determina la exclusión social. Como apuntábamos en apartados anteriores, la pobreza se refiere a las situaciones en las que hay carencia o falta de recursos materiales o económicos, por lo que podríamos decir que las familias a las que entrevistamos eran pobres, por lo que sus hijas e hijos también lo eran. La exclusión social, por su parte, hace referencia a la acumulación de dificultades en el empleo, la vivienda, la salud, la educación, las relaciones personales, la participación política y social, o los recursos económicos. Reflexionando ahora en cada uno de los ámbitos enumerados y enlazándolos con los resultados de las entrevistas, podríamos decir que, sin entrar en grados o niveles de exclusión, las y los miembros de estas familias podrían estar en riego de exclusión social.

La falta de empleo en el seno de estas familias fue el origen de los problemas de impago. En el momento de la entrevista, las participantes estaban en el paro y buscaban trabajo. La falta de empleo había hecho que no pudiesen pagar las cuotas de la hipoteca a la entidad financiera y que, aunque habían conseguido una demora de dos años, en un caso, y en el otro, hasta mayo de 2015, sabían que la casa estaba perdida. Si a esa futura pero segura falta de vivienda le sumamos la preocupación, los sentimientos de culpabilidad y vergüenza, la depresión y el cansan- cio, y los prejuicios de la gente, es lógico pensar que todo ello haya deteriorado la salud de las y los miembros del núcleo familiar. La educación también fue un ámbito que se vio afectado, al empeorar el rendimiento académico e incluso producirse un abandono escolar. Las relaciones personales también se vieron dañadas, pues hubo que cambiar de círculo de amistades por los prejuicios ante la falta de dinero. Si a esto le unimos la escasez de actividades lúdicas, de ocio -sea por cansancio de las madres o padres, 0 por la falta de recursos-, el ámbito de las relaciones sociales también se vio perjudicado, junto con el de la participación social.

Partiendo de la idea de que los derechos humanos son interdependientes e indivisibles, podríamos concluir este artículo afirmando que en los procesos de desahucio se vulneran los derechos de la infancia. Desde el momento en que un elemento tan primordial como es la vivienda para el bienestar y desarrollo de una niña o un niño queda en un segundo plano, y priman los intereses de una entidad financiera, la vulneración de derechos es una realidad. En estos procesos, la infancia no tiene oportunidad alguna de exigir sus derechos por sí misma, ni tampoco mediante representación, como se ha constatado en el análisis.

Que los derechos de la infancia queden vulnerados en los procesos de desahucio no es algo puntual, es algo que va a perdurar en el tiempo. La deuda que tienen sus madres y padres no cesa con la pérdida de la vivienda. La deuda será la mochila que lleve la familia durante muchos años, y gran parte del ejercicio de sus derechos se verá influenciado por esa mochila. La imposibilidad de volver a pedir un préstamo, la dificultad de conseguir contratos de luz o teléfono, el embargo de cierta cantidad del sueldo una vez encontrado un trabajo, la necesidad de buscar un trabajo sin contrato para que no les embarguen el sueldo, o aparecer en listas de morosos impide comenzar la vida desde cero.

Creemos que los resultados nos han acercado a la realidad de la infancia afectada en un proceso de desahucio y al análisis de sus derechos fundamentales. Somos conscientes de que estos resultados no son generalizables a todas las familias y a la infancia que se encuentra en estas situaciones de pérdida de la vivienda en Gipuzkoa, pero sí que podrían ser representativos de la situación que atraviesan muchas familias. Dada la escasez de estudios sobre el efecto de los desahucios en la población en general, y en la infancia en particular, este artículo podría ser, además, un pequeño punto de partida para seguir abordando esta línea de investigación. 
AGENCIA EFE (2013): Una juez de Madrid para un desahucio hasta que acabe el curso escolar, Madrid, 22-4-13 [<http://www.abc.es/ espana/20130421/abci-juez-desahucio-cursoescolar-201304211055.html>].

ÁLVAREZ-GAYOU, J. L. (2003): Cómo hacer investigación cualitativa. Fundamentos y metodología, México, Paidós.

ARARTEKO (2013a): El impacto de la crisis en la infancia: la realidad vasca. Una reflexión cuantitativa, Vitoria-Gasteiz, Ararteko [«http://www.ararteko.net/RecursosWeb/ DOCUMENTOS/1/o_2968_3.pdf〉].

- (2013b): Informe Anual al Parlamento Vasco 2013, VitoriaGasteiz, Ararteko [<http://www.ararteko.net/ RecursosWeb/DOCUMENTOS/1/o_3301_3.pdf)].

BANCO DE ESPAÑA (2014): Nota informativa sobre los procesos de ejecución hipotecaria sobre viviendas, Banco de España, 19-5-14 [khttp:// www.bde.es/f/webbde/GAP/Secciones/ SalaPrensa/NotasInformativas/Briefing_notes/ es/notabe190514.pdf)].

BLAXTER, L; HUGHES, C.; y TIGHT, M. (2008): ¿Cómo se investiga?, Barcelona, Graó.

CAMPOY, I. (1998): “Notas sobre la evolución en el reconocimiento y la protección internacional de los derechos de los niños", Derechos y Libertades. Revista del Instituto Bartolomé de las Casas, vol. 3, nㅜ 6, págs. 279-328.

CÁRDENAS MIRANDA, E. (2011): “El interés superior del niño", Revista de Letras Jurídicas, no 23 , págs. 213-226 [<http://www.letrasjuridicas. com/Volumenes/23/18a.pdf〉].

CARDONA, J. (2012): "La Convención sobre los Derechos del Niño: significado, alcance y nuevos retos",
Educatio Siglo XXI, vol. 30, n- 2, págs. 47-68 ['http://hdl.handle.net/10201/38707〉].

CÁRITAS (2013): VIII Informe del Observatorio de la Realidad Social: empobrecimiento y desigualdad social, Equipo de Estudios Cáritas Española [«http:// www.elcorreo.com/apoyos/documentos/VIIIinforme-caritas.pdf`].

CASAS, F. (1998): Infancia: perspectivas psicosociales, Barcelona, Paidós.

COLAU, A.; y ALEMANY, A. (2013): 2007-2012: Retrospectiva sobre desahucios y ejecuciones hipotecarias en España, estadísticas oficiales e indicadores, Plataforma de Afectados por la Hipoteca [khttp://afectadosporlahipoteca.com/wpcontent/uploads/2013/02/RETROSPECTIVASOBRE-DESAHUCIOS-Y-EJECUCIONESHIPOTECARIAS-EN-ESPA\%C $3 \% 91$ ACOLAUALEMANY1.pdf $>$.

COMISARIO PARA LOS DERECHOS HUMANOS DEL CONSEJO DE EUROPA (2013): Informe por Nils Muižnieks, Comisario para los Derechos Humanos del Consejo de Europa, tras su visita a España, del 3 al 7 de junio de 2013, Estrasburgo, Comisario para los Derechos Humanos del Consejo de Europa [rhttps://wcd.coe.int/com.instranet. InstraServlet? command=com.instranet. $C \mathrm{mdBlo}$ bGet $\&$ Instranet Image $=2356738 \&$ SecMode $=1 \&$ Docld $=2056532 \&$ Usage $=2>$ ].

COMPTE NUNES, G. (2011): “La institucionalización de la participación infantil en un servicio de protección de niños y niñas en riesgo", Revista sobre la Infancia y la Adolescencia, no 8, págs. 44-74 [«http://dx.doi.org/10.4995/ reinad.2015.3153>].

CONSEJO GENERAL DEL PODER JUDICIAL (2013): “Una aproximación a la conciliación de los datos 
sobre ejecuciones hipotecarias y desahucios", Datos de Justicia. Boletín de Información Estadística, nํ-35 [rhttp://www.poderjudicial. es/cgpj/es/Temas/Estadistica_Judicial/ Analisis_estadistico/Datos_de_la_Justicia/ Conciliacion_de_datos_sobre_ejecuciones_ hipotecarias_y_desahucios_N_ junio_2013_’].

DÁVILA, P.; y NAYA, L. M. (eds.) (2011): Derechos de la infancia y educación inclusiva en América Latina, Buenos Aires, Granica.

- (coords.) (2010): Infancia, derechos y educación en América Latina, Donostia, Erein.

ESPAÑA (2015): “Ley 15/2015, de 2 de julio, de la Jurisdicción Voluntaria”, Boletín Oficial del Estado, no 158 , 3-7-15, págs. 54.068-54.201 [rhttps://www.boe.es/diario_boe/txt. php?id=BOE-A-2015-73911] .

- (2013): “Ley $1 / 2013$, de 14 de mayo, de Medidas para Reforzar la Protección a los Deudores Hipotecarios, Reestructuración de Deuda y Alquiler Social", Boletín Oficial del Estado, no 116, 15-5-2013, págs. 36.373-36.398 [ khttp:// www.boe.es/boe/dias/2013/05/15/pdfs/ BOE-A-2013-5073.pdf>].

- (1978): “Constitución Española”, Boletín Oficial del Estado, 29-12-1978, no 311, págs. 29.31329.424 [ [https://www.boe.es/buscar/act. php?id=BOE-A-1978-31229»].

ETXEBIDE (2011): “Servicio de Ayuda al Sobreendeudamiento Familiar del Gobierno Vasco", Gobierno Vasco [<http://www.etxebide. euskadi.eus/x39-contpest/es/contenidos/ informacion/servic_mediac_hipo/es_etxecont/ etxecont.htmlı].

GAITÁN, L. (2006): Sociología de la infancia: nuevas perspectivas, Madrid, Síntesis.

GOBIERNO VASCO (2012): Encuesta de Pobreza y Desigualdades Sociales. Principales resultados, Vitoria-Gasteiz, Departamento de Empleo y Asuntos Sociales [<http://www.gizartelan.ejgv. euskadi.eus/contenidos/informe_estudio/ epds_2012/es_epds2012/adjuntos/ EPDS_2012es.pdf»].

JIMÉNEZ, M.; LUENGO, J. J.; y TABERNER GUASP, J. (2009): "Exclusión social y exclusión educativa como fracasos. Conceptos y líneas para su comprensión e investigación", Profesorado. Revista de Currículum y Formación del Profesorado, vol. 13, no 3, págs. 11-49 [<http:// www.ugr.es/local/recfpro/rev133ART1.pdf〉].

MIGUELENA TORRADO, J. (2014): “Los derechos de las niñas, niños y adolescentes en situación de desahucio. El caso de Gipuzkoa" [inédito], Máster de Investigación en Ámbitos Socioeducativos, Universidad del País Vasco (UPV/EHU) [rhttps:// addi.ehu.es/bitstream/10810/15282/1/ LOS\%20DERECHOS\%20DE\%20LAS\%20 $\mathrm{NI} \% \mathrm{C}_{3} \% 91 \mathrm{AS}, \% 20 \mathrm{NI} \% \mathrm{C}_{3} \% 910 \mathrm{O} \% 20$ Y\%20ADOLESCENTES\%20EN\%20 SITUACI\%C3\%93N\%20DE\%2ODESAHUCIO.\%20 joana\%2omiguelena\%20(2)\%20(1).pdf $)$.

QVORTRUP, J. (1992): “El niño como sujeto y como objeto: ideas sobre el programa de infancia en el Centro Europeo de Viena", Infancia y Sociedad, no ${ }_{15}$, págs. 168-186.

SIIS CENTRO DE DOCUMENTACIÓN Y ESTUDIOS (2013): Pobreza infantil en Euskadi, Vitoria-Gasteiz, Eusko Jaurlaritza-Gobierno Vasco [rhttp:// www.siis.net/es/documentacion/catalogo/ Record/193385'].

SUBIRATS, J. (dir.) (2004): Pobreza y exclusión social: un análisis de la realidad española y europea, Barcelona, Fundación La Caixa [<http://www. ciimu.org/images/stories/CIIMU/Lecturas_ recomendadas/pobreza_exclusion_social_ subirats_lacaixa_16.pdf>]

TAYLOR, S. J.; y BODGAN, R. (1986): Introducción a los métodos cualitativos de investigación. La búsqueda de significados, Barcelona, Paidós.

TRIBUNAL EUROPEO DE DERECHOS HUMANOS (2013): "Application no. 62688/13. Ceesay Ceesay and Others v. Spain", Estrasburgo, Tribunal Europeo de Derechos Humanos, 15-10-13 [<http:// www.ara.cat/societat/Diligencia-PAH-jutjat ARAFIL20131016_0002.pdf)].

UNICEF COMITÉ ESPAÑOL (2006): Convención sobre los Derechos del Niño, Madrid, Unicef Comité Español [<http://www.unicef.es/sites/www. unicef.es/files/CDN_06.pdf〉].

UNICEF ESPAÑA (2012): La infancia en España 2012-2013: el impacto de la crisis en los niños, Madrid, Unicef España [<http://www.unicef.es/sites/www. unicef.es/files/Infancia_2012_2013_final.pdf〉].

VALIÑO, V. (coord.) (2013): Emergencia habitacional en el Estado español. La crisis de las ejecuciones hipotecarias y los desalojos desde una perspectiva de derechos humanos, Barcelona, Observatori DESC; Barcelona, Plataforma de Afectados por la Hipoteca [rhttp:// afectadosporlahipoteca.com/tag/emergenciahabitacional/>l.

VERHELLEN, E. (2002): La convención sobre los derechos del niño: trasfondo, motivos, estrategias, temas principales, Garant. 